\title{
Performance Studies of PEFCs Incorporating Non-woven Metal Fabric as Flow Fields for Even Supply of Reactants
}

\author{
Shun Fujita $^{1)}$ Shunri Hirasawa $^{2)}$ Toshio Shudo ${ }^{2)}$ \\ 1) Tokyo Metropolitan University, Department of Mechanical Engineering \\ 1-1 Minamiosawa, Hachioji, Tokyo 192-0397, Japan \\ 2) Tokyo Metropolitan University, Department of Applied Chemistry for Environment (E-mail: shudot@tmu.ac.jp) \\ 1-1 Minamiosawa, Hachioji, Tokyo 192-0397, Japan
}

Received on December 21, 2018

\begin{abstract}
Previous research shows that the power density of polymer electrolyte fuel cell can be increased by applying porous metal as a flow fields, supplying reactants evenly to the whole electrode areas as compared to the operation with conventional groove type flow fields. This paper investigates the effect of introducing none-woven metal fabric as flow fields. The investigations here revealed that the metal fabric shows higher maximum power output than groove due to a reaction resistance reduction. The effects above was observed in various flow feeds. The reduction of the resistance was significant in cathode, due to better water transport.
\end{abstract}

KEY WORDS: EV and HV systems, fuel cell / polymer electrolyte fuel cell, non-woven metal fabric, porosity [A3]

\section{Introduction}

The performance of polymer electrolyte fuel cell (PEFC) should be further improved as it powers fuel cell vehicles ${ }^{(1)}$. Separators (i.e. bipolar plates) that are located beside membrane electrode assembly (MEA), providing reactants (i.e. hydrogen and oxygen) to MEA, transfers electricity to neighboring parts, and collects water generated from MEA. Therefore, separators highly affect the performance of PEFC ${ }^{(2)}$. Majority of the separators in PEFC has groove craved on its surface as a flow field of reactants ${ }^{(3)}$. This structure is unable to provide reactants evenly to MEA as the rib in the flow field covers the surface of MEA ${ }^{(4)}$. For this reason, our research team uses porous metal as flow fields. Previous research shows that the power density of PEFC can be increased by porous metal as a flow fields, supplying reactants evenly to the whole electrode areas as compared to the operation with conventional groove type flow fields ${ }^{(4)-(9)}$. The research here introduces non-woven metal fabric as flow fields. The metal fabric is expected to enable even supply of reactants as it has highly porous sheet structures. The research here analyzes influence of the metal fabric on power output by making performance comparison between conventional serpentine groove flow field.

\section{Experiments}

The setup of the tested single cell is schematically shown in Fig. 1. Separators shown in Fig.2 were equipped in the standard cell devised by Japan Automobile Research Institute (JARI). In the case of separator with non-woven metal fabric (NWMF), sheet shaped NWMF was located beside SUS316L block to act as a flow field. Table 1 shows the specifications of the tested NWMF. The current research tested a separator flow field formed in a highly porous structure as shown in Fig. 3. It has a porosity of around $85 \%$ and $0.3 \mathrm{~mm}$ thickness. Ti was used to achieve good corrosion-resisting properties. For comparison, solid stainless- steel separators as shown in Fig. 2 were used. Flow field craved on its surface has same geometry as graphite serpentine groove in JARI standard cell.

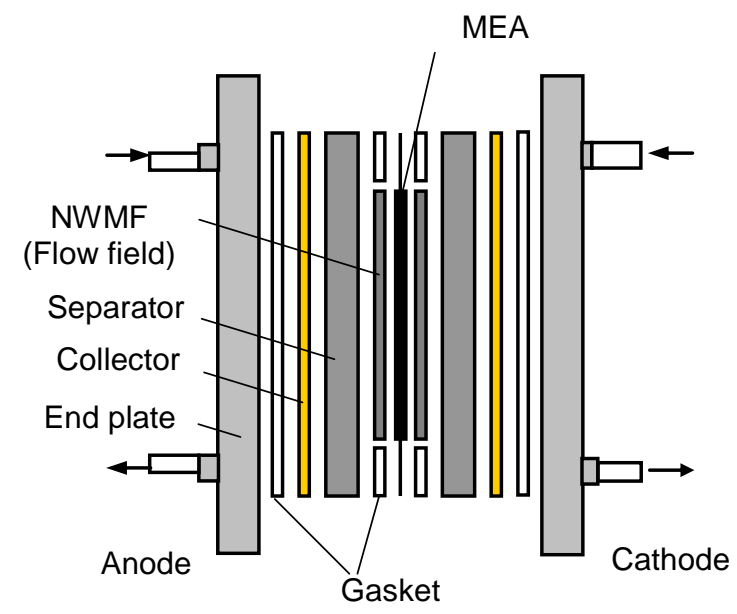

Fig. 1 Setup of tested fuel cell with non-woven metal fabric.

Table 1 Specification of tested non-woven metal fabric.

\begin{tabular}{|c|c|}
\hline Composition & Titanium \\
\hline Flow field area & $25 \mathrm{~cm}^{2}(5 \times 5 \mathrm{~cm})$ \\
\hline Thickness & $0.3 \mathrm{~mm}$ \\
\hline Porosity & $85 \%$ \\
\hline
\end{tabular}




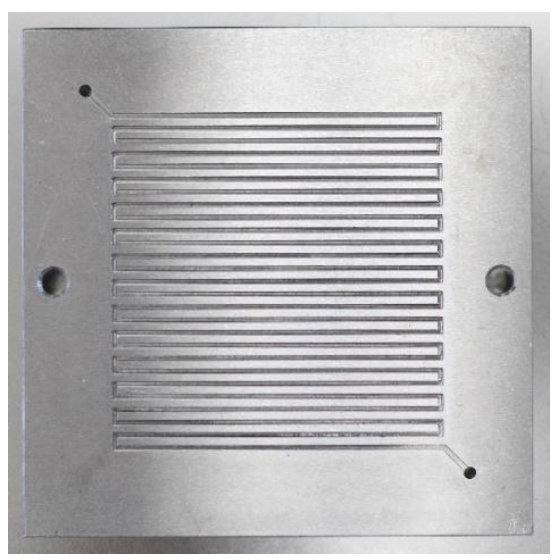

(a)

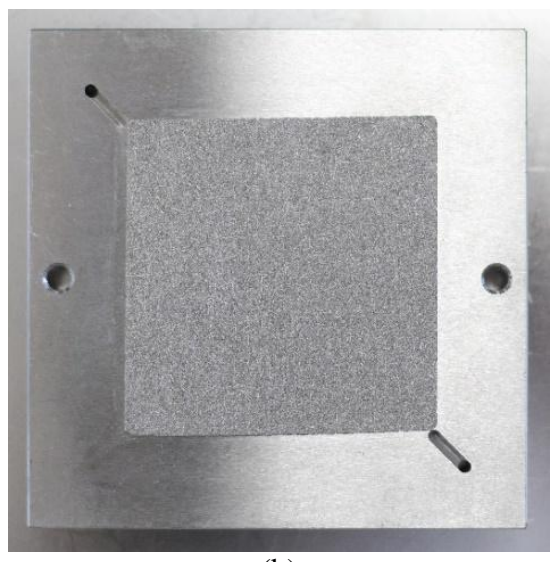

(b)

Fig. 2 Separators with different flow fields used here: (a) solid stainless steel with a groove type flow field and (b) non-woven metal fabric flow field.

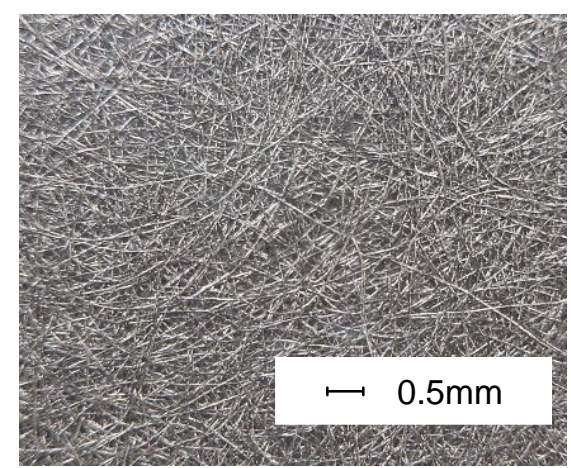

Fig. 3 Photomicrograph of the non-woven metal fabric.

Specifications of the tested membrane electrode assembly (MEA) are shown in Table 2. The catalyst loading on each electrode was $1 \mathrm{mg} / \mathrm{cm}^{2}(\mathrm{Pt})$. The catalysts are with carbon support. A Nafion NR-212 polymer electrolyte membrane was sandwiched between the electrodes. Carbon paper was used as gas diffusion layer (GDL) on both sides of the MEA. The cathode gas flow rate was controlled with a needle valve and measured with a mass flow meter. Cell temperature and anode feed temperature were controlled with rubber heaters attached beside the end plates. Gas flow rates and each temperature were controlled by integrated fuel cell testing system. (Toyo Corporation Minitest 3000). Fuel cell output power was measured with a fuel cell load unit coupled with a frequency response analyzer unit for impedance measurement (Scriber Associates 890 series).

Table 2 MEA specification

\begin{tabular}{|c|c|}
\hline PEM & Nafion NR-212 $(\mathrm{t}=50.8 \mu \mathrm{m})$ \\
\hline Reaction area & $25 \mathrm{~cm}^{2}(5 \times 5 \mathrm{~cm})$ \\
\hline Catalyst & $1 \mathrm{mg} / \mathrm{cm}^{2}-\mathrm{Pt}$ \\
\hline GDL & $\mathrm{SGL} \mathrm{GDL} 29 B C$ \\
\hline
\end{tabular}
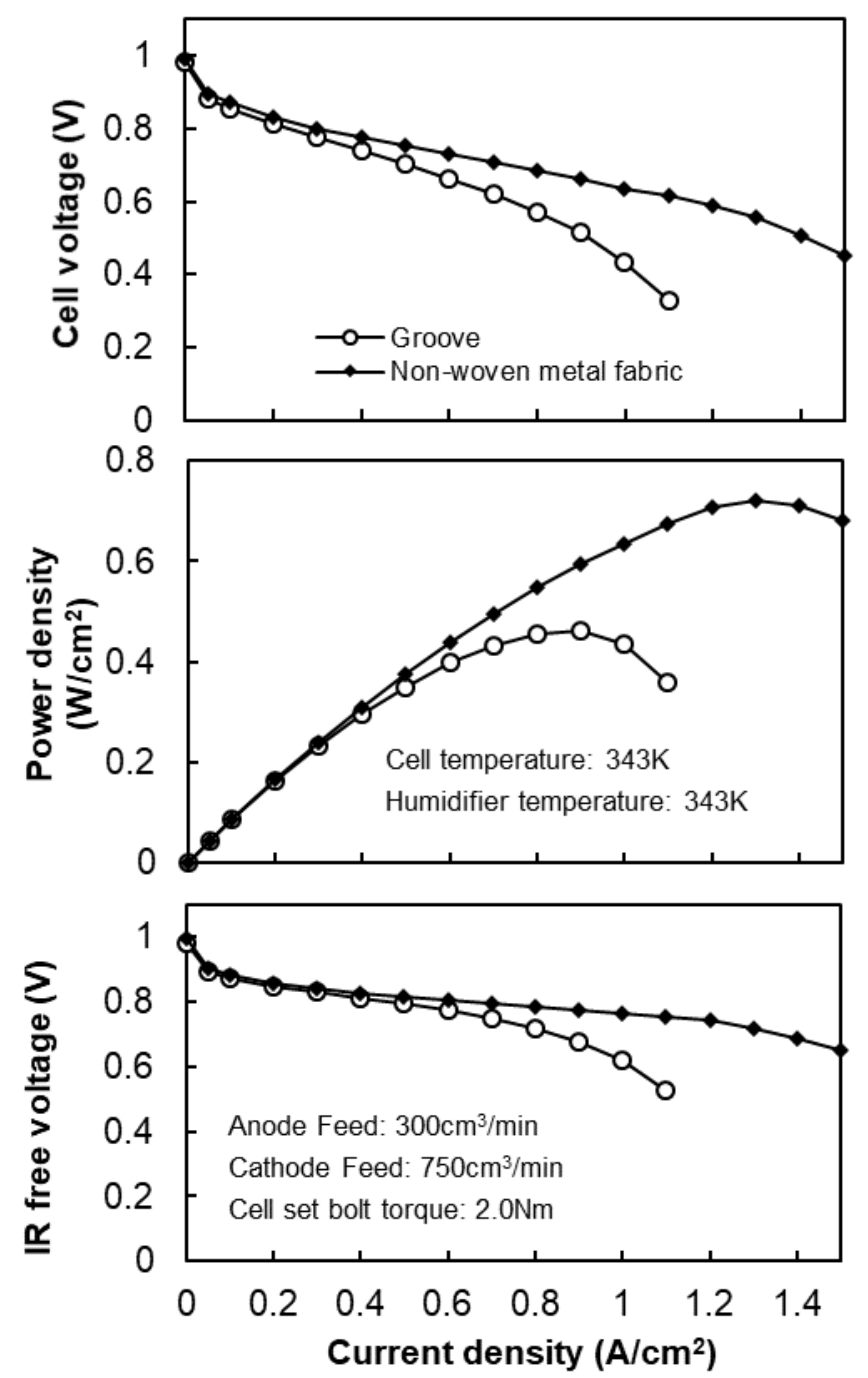

Fig. 4 Cell performance with non-woven metal fabric and groove flow fields.

\section{Results and discussions}

\subsection{Effect of NWMF flow fields on cell performance}

Fig. 4 shows cell voltage, power density and IR free voltage versus current density at $343 \mathrm{~K}$ cell temperature with NWMF or serpentine groove on both electrodes. The anode feed rate was $300 \mathrm{~cm}^{3} / \mathrm{min}$ and the cathode feed rate were $750 \mathrm{~cm}^{3} / \mathrm{min}$. These flow fields give similar performance under a $0.1 \mathrm{~A} / \mathrm{cm}^{2}$ current density. However, NWMF enables the cell to operate with higher voltage at current densities over $0.1 \mathrm{~A} / \mathrm{cm}^{2}$. This results higher output power especially at higher current density conditions where concentration polarization usually lowers the cell performance. To investigate this effect, the cell internal resistance 
free voltage, iR free voltage was also measured. The $i R$ free voltage behavior refers to the intensity of reaction resistance consisted of activation loss and concentration loss. The result indicates significant voltage drop of groove in high current density conditions signifying severe reaction resistance which diminishes cell output power.

Other measurements were made to obtain the AC impedance of the cells at $1.1 \mathrm{~A} / \mathrm{cm}^{2}$ for both flow field types, the condition of which the highest current density drawn with both of flow field types. The impedance spectra were evaluated at frequencies from $5 \mathrm{kHz}$ to $0.03 \mathrm{~Hz}$. Fig. 5 shows the imaginary part $\mathrm{j} X$ and real part $R$ of the measured complex impedance $Z$ :

$$
=R+\mathrm{j} X
$$

The results indicate that the arc diameter, which corresponds to reaction resistance is smaller for the NWMF case than that for the groove case. The result signifies that the NWMF flow field improves reactants and product diffusion that realizes even supply of hydrogen and oxygen to the electrodes. It is conceivable that the effective electrode area was increased by the NWMF as it has no ribs which may act as an obstacle to the reactant supply and product removal with the groove flow field.

Apart from reaction resistance, cell internal resistance (i.e. cell resistance) that includes electrical resistance of cell parts, interfacial contact resistance and proton transfer resistance corresponds to one of the intersections of the arc with real axis, closer to the origin. The result shows the case with NWMF has lower cell resistance than that of groove. Rough surface of NWMF may have been an important factor in making contact resistance of NWMF smaller.

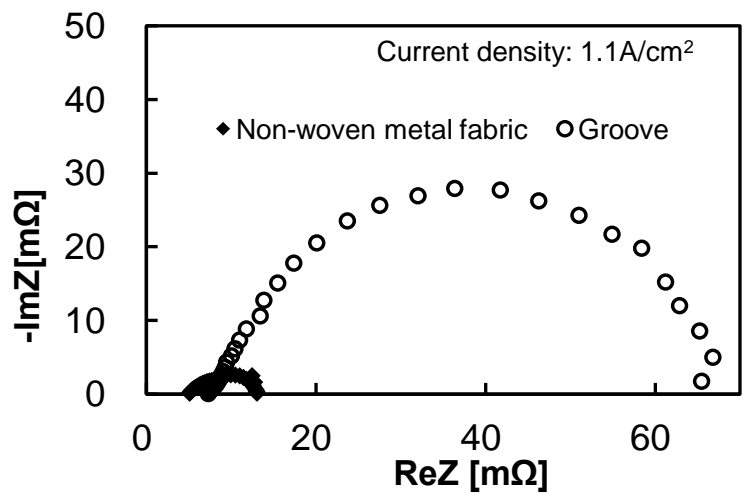

Fig. 5 Impedance plots for non-woven metal fabric and groove flow fields.

\subsection{Cell performance comparison at various flow feeds}

The influence of reactants feed rates on performance of the cell with groove and NWMF are shown in Fig. 6 and Fig. 7 respectively. The experimental conditions for each case were same as previous experiment except for the flow feeds, which has been altered from original flow feed of $300 \mathrm{~cm}^{3} / \mathrm{min}$ for anode and $750 \mathrm{~cm}^{3} / \mathrm{min}$ for cathode. Cell voltage on both flow fields increases as flow feed rate rises. It seems probable that the more reactant feed rate increases, the more gas would be supplied to the electrodes causing the reduce in reaction resistance. As regards cell power output, Fig. 8 compares the maximum power density of both flow fields at different flow feed rates. What stands out in the figure is the dominance of NWMF maintaining higher performance than the groove at any feed rate. This may caused by high gas diffusibility of NWMF, that has no ribs which may act as an obstacle to the reactant supply and product removal with conventional groove flow fields.

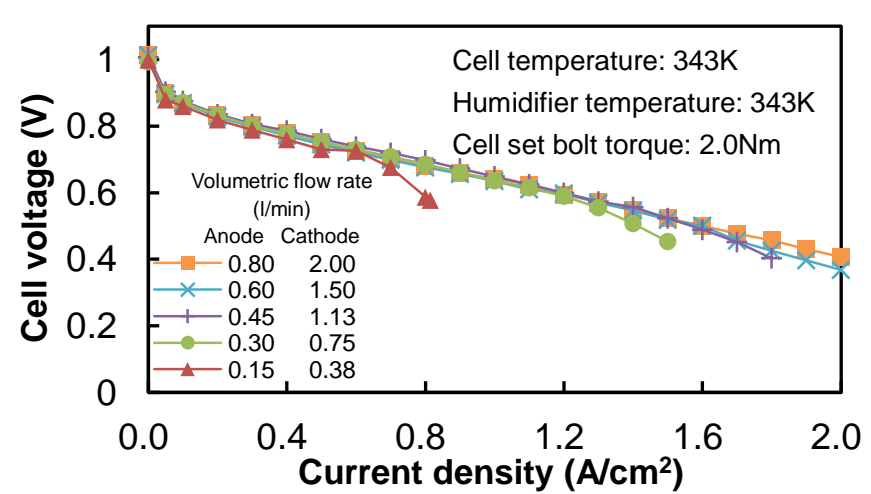

Fig. 6 Influence of feed rate on performance of the cell with nonwoven metal fabric.

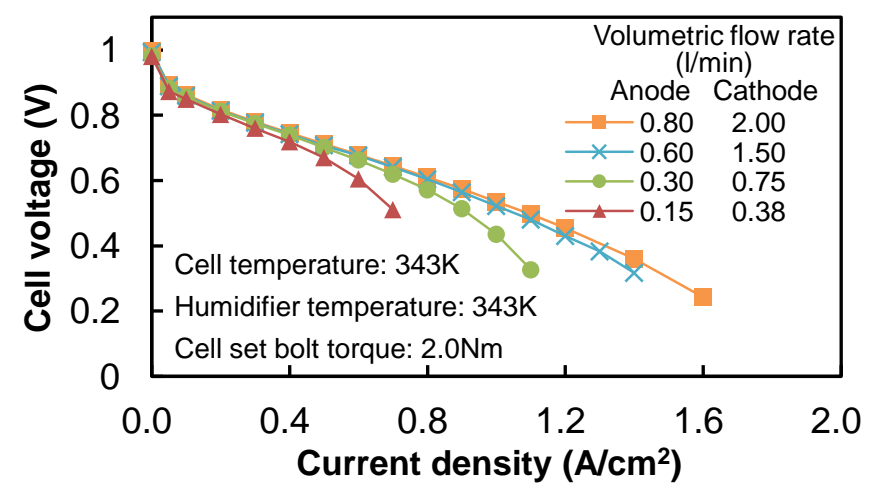

Fig. 7 Influence of feed rate on performance of the cell with groove.

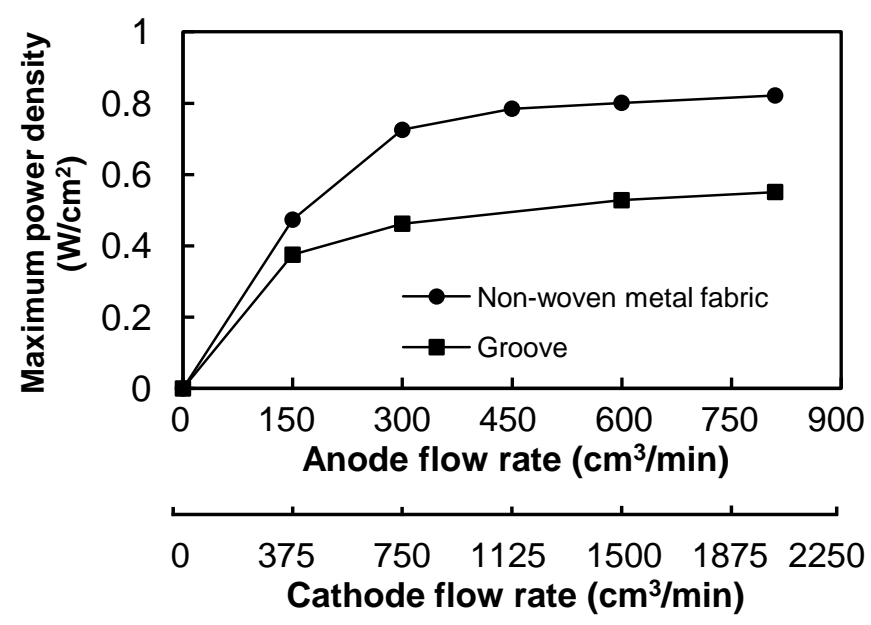

Fig. 8 Dependence of maximum power density on volumetric flow rate of reactants.

In terms of maximum power density transitions, they stabilized as the feed rates increases. To investigate this effect, $\mathrm{AC}$ impedance spectra of the cell with NWMF and groove were severally shown in Fig. 9 and Fig. 10, both obtained at $0.6 \mathrm{~A} / \mathrm{cm}^{2}$. Transition of the arc diameters depending on flow rate were compared in Fig. 11, showing convergence-trend which has also been suggested in the comparison of maximum power density in Fig.8. Therefore, it can be claimed that the cell power output alternation predominantly originated from changes in reaction resistance. Reaction resistance decrease may have been caused by increase in reactant flow speed, as it facilitates reactant absorption 
to electrode. Consequently that lead to reaction resistance reduction resulting in higher maximum power output. On the other hand, the finite electrode surface may impede further absorption of reactants. This could be one of the reasons for the hovers in reaction resistance and maximum power output.

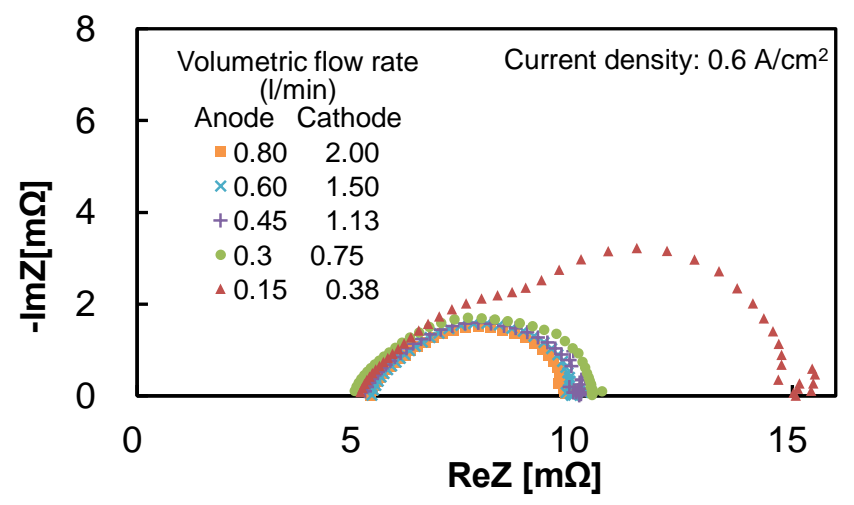

Fig. 9 Impedance spectra of the tested cell with non-woven metal fabric at different volumetric flow rate of reactants.

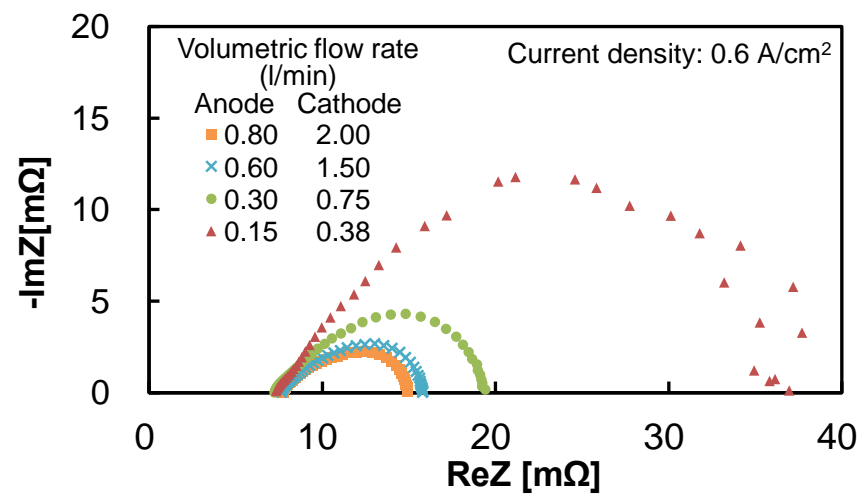

Fig. 10 Impedance spectra of the tested cell with groove at different volumetric flow rate of reactants.

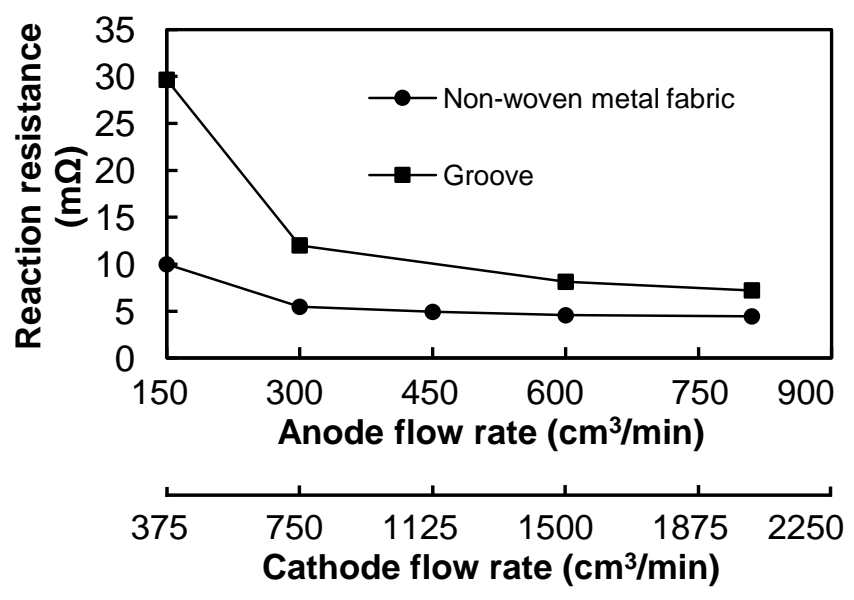

Fig. 11 Dependence of cell reaction resistance on volumetric flow rate of reactants.

\subsection{Each effect of NWMF flow fields on anode and cathode}

This section attempts to separate the effects of NWMF flow field on anode and cathode. The results indicated in Fig. 12 were obtained at the temperature of $343 \mathrm{~K}$ with the anode feed rate of $300 \mathrm{~cm}^{3} / \mathrm{min}$ and the cathode feed rate of $750 \mathrm{~cm}^{3} / \mathrm{min}$. Triangular symbols are with the conventional groove flow field on the anode and the NWMF flow field on the cathode. Solid circular symbols are with the NWMF flow field on the anode and the groove flow field on the cathode. Results with the groove flow fields on both electrodes are also shown with open circular symbol for comparison. The anode feed rate was $300 \mathrm{~cm}^{3} / \mathrm{min}$ and the cathode feed rate $750 \mathrm{~cm}^{3} / \mathrm{min}$. In both experiments, NWMF flow field achieves higher output power than the groove flow field especially at higher current densities and, furthermore, the effect is higher at the cathode where water is generated as a product. Similar trend was observed in iR free voltage suggesting that the NWMF is effective to improve cell performance by decrease in reaction resistance due to the smoother water removal from the cathode.
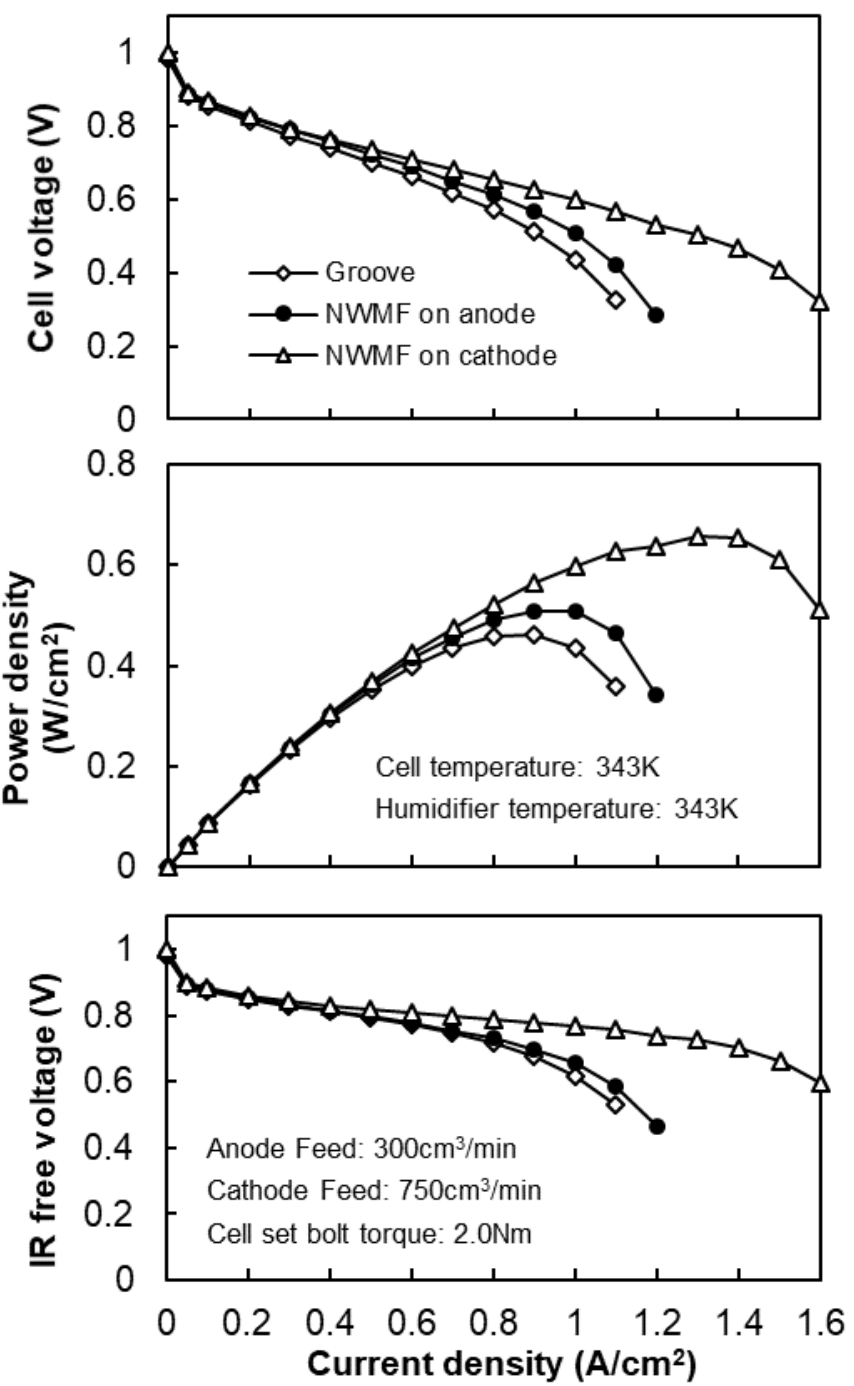

Fig. 12 Effect of non-woven metal fabric on each electrode.

AC impedance spectra shown in Fig. 13 were obtained at $1.1 \mathrm{~A} / \mathrm{cm}^{2}$. The result shows the reaction resistance is smallest with NWMF on the cathode followed by that on the anode the order of which is identical to the $\mathrm{iR}$ free voltage drop. Thereby, it can be claimed that the effect of performance improvement due to decrease in reaction resistance is also conceivable from AC impedance measurement. 


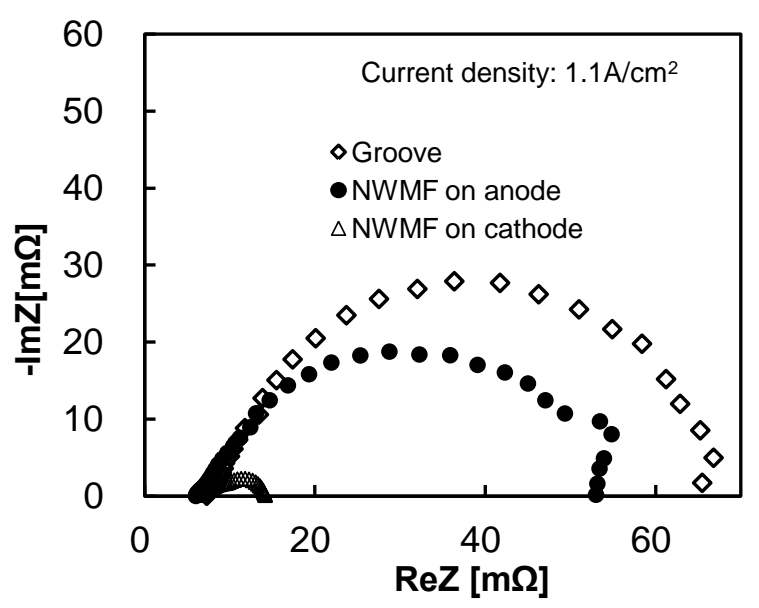

Fig. 13 Impedance plots for groove flow field and non-woven metal fabric flow field on anode or cathode.

\section{Conclusion}

(1) By employing a non-woven metal fabric with around $85 \%$ porosity as the flow field in separators, performance of a polymer electrolyte fuel cell is improved, compared to operation with conventional groove type flow fields. The improvement would be attributed to the increased effective electrode area by the metal fabric flow field because it has no ribs which may act as an obstacle to the reactant supply and product removal with conventional groove flow fields.

(2) Increase in flow feed rate improves performance of the tested cells regardless of the flow field types. The cell with non-woven metal fabric achieves higher maximum power output at any flow feed rate tested. Higher gas diffusibility by the metal fabric may have contributed to the reaction resistance reduction resulting in the cell performance improvements.

(3) The improved cell performance by the non-woven metal fabric flow field is better at the cathode than at the anode. The metal fabric would improve the reactant supply to and product removal from electrodes. Because of this, concentration loss decreases, and cell performance is improved especially at higher current densities.

\section{References}

(1) K. Seong, J. Byeong, S. Oh: Fuel economy and life-cycle cost analysis of a fuel cell hybrid vehicle: Journal of Power Sources, Vol.105, Issue 1, pp.58-65, (2002).

(2) A. Hermann, T. Chaudhuri, P. Spagnol: Bipolar plates for PEM fuel cells: A review, International Journal of Hydrogen Energy, Vol.30, Issue 12, pp.1297-1302 (2005).

(3) A. Kumar, R.G. Reddy, Materials and design development for bipolar/end plates in fuel cells, Journal of Power Sources, Vol.129, Issue 1, pp.62-67, (2004).

(4) E. Hontañón, M.J. Escudero, C. Bautista, P.L. García-Ybarra, L. Daza, Optimisation of flow-field in polymer electrolyte membrane fuel cells using computational fluid dynamics techniques, Journal of Power Sources, Vol.86, Issues 1-2, pp.363-368, (2000).

(5) S. Arisetty, A.K. Prasad, S.G. Advani: Metal foams as flow field and gas diffusion layer in direct methanol fuel cells. Journal of Power Sources, Vol.165, Issue 1, pp.49-57, (2007).

(6) T. Shudo, K. Suzuki: Performance improvement in direct methanol fuel cells using a highly porous corrosion-resisting stainless steel flow field, International Journal of Hydrogen Energy, Vol.33, Issue 11, pp.2850-2856, (2008).

(7) B. Tsai, C. Tseng, Z. Liu, C. Wang, C. Lee, C. Yang, S. Lo, Effects of flow field design on the performance of a PEM fuel cell with metal foam as the flow distributor, International Journal of Hydrogen Energy, Vol.37, Issue 17, pp.13060-13066, (2012).

(8) N.K. Shrivastava, S.B. Thombre, R.V. Motghare, Wire mesh current collectors for passive direct methanol fuel cells, Journal of Power Sources, Vol.272, pp.629-638, (2014).

(9) H. Matsumoto, S.Fujita, T. Shudo: Research on Performance Improvement in Polymer Electrolyte Fuel Cell, Proceedings of the $36^{\text {th }}$ Congress of Hydrogen Energy Systems Society of Japan, pp.107-110, (2016). 